\title{
Utilization of insecticide treated nets in Arbaminch Town and the malarious villages of Arbaminch Zuria District, Southern Ethiopia
}

\author{
Ayalew Astatkie ${ }^{1}$, Amsalu Feleke ${ }^{2}$
}

\begin{abstract}
Introduction: Malaria causes an overwhelmingly large number of cases and deaths round the globe every year. Insecticide treated nets (ITNs) have become important tools that provide a simple, but effective means of preventing malaria in highly endemic areas.

Methods: A community-based cross-sectional study design was used to investigate possession, utilization, and factors affecting possession and utilization of ITNs in Arbaminch Town and the malarious villages of Arbaminch Zuria District, southern Ethiopia from $22^{\text {nd }}$ January to $1^{\text {st }}$ February 2007 on a sample of 454 households. Data were collected using structured, pretested, interviewer-administered questionnaire. Data entry and analysis was performed using SPSS 11.0 for windows. Univariate, bivariate and multivariate analyses were carried out.

Results: The coverage for any net and ITN was $75.1 \%$ and $58.8 \%$ respectively; the utilization rate for any net and ITN by any member of the household the night prior to the study was $71 \%$ and $73 \%$ respectively. Both coverage and utilization were higher in rural areas than in urban areas. The proportion of pregnant women and children under five years who slept under ITNs the night preceding the study was 35\% and $40.3 \%$ respectively. Education and income of head of households, place of residence of households and presence of high risk groups in the household were found to be predictors of net possession. Sex and income of head of households, and presence of radio in the households were predictors of utilization of nets by any household member. Education of head of households and place of residence of households were predictors of utilization of nets by high risk groups.

Conclusions: A wide gap exists between coverage and utilization of ITNs. Use of ITNs by high risk groups is far below the Abuja target. Appropriate BCC interventions are required to narrow the gap between coverage and utilization of ITNs and to escalate use of ITNs by high-risk groups. [Ethiop. J. Health Dev. 2009;23(3):206-215]
\end{abstract}

\section{Introduction}

Malaria remains one of the world's most significant health and development problems. An estimated number of 300-500 million malaria cases and more than one million deaths that are directly attributable to malaria worldwide occur every year. More than $90 \%$ of the clinical cases and deaths occur in Africa south of the Sahara Desert $(1,2,5)$. Of those Africans who die from malaria each year, most are children under five years of age (6). Pregnant women are also more susceptible than non-pregnant women due to altered level of immunity. The disease is estimated to be responsible for an estimated average annual reduction of $1.3 \%$ in economic growth for those countries with the highest burden $(1,6)$.

In Ethiopia, malaria is a leading public health problem (7-9). Three quarters of the land mass (altitude $<2000$ meters) is regarded as malaria affected (10), and about two-thirds $(68 \%)$ of the population is at risk of malaria (2, $8-10)$. It is estimated that the annual number of malaria cases is approximately 4-5 million, with 70,000 deaths. The disease case fatality ranges from $17-35 \%(10)$. In the year 2004/05, malaria was the leading cause of outpatient visit $(16.57 \%)$, admission (14.98\%) and death $(28.9 \%)$ (11). What makes things worse is that to-date there is no safe, effective and affordable anti-malarial drug that can be used for chemoprophylaxis at a large scale (8).

Insecticide-treated nets (ITNs) have become important tools that provide a simple and effective means of preventing malaria in highly endemic areas (4). At present large scale ITN programs are being implemented in sub-Saharan Africa, Asia and Latin America using a number of operational approaches (12).

Large-scale trials of ITNs have demonstrated that they reduce malaria mortality and morbidity under a variety of epidemiological conditions (1-3, 12-20). Results from such studies provide enough evidence to galvanize consensus in the global community that provision of ITNs should receive priority (1). At the African summit on Roll Back Malaria in Abuja, Nigeria in April 2000, heads of states and senior representatives from 44 malaria afflicted countries in Africa agreed to a goal of providing ITNs to at least $60 \%$ of those at risk of malaria, particularly pregnant women and children less than five years of age, by $2005(1,10,18,19,21,22)$. This target has also been set by the Ministry of Health and Roll Back Malaria partners in Ethiopia (2). But coverage in Africa is still unacceptably low $(22,23)$ : only $3 \%$ of African children are sleeping under ITN, and only about $20 \%$ are

${ }^{1}$ University of Hawassa, College of Health Sciences, Faculty of Public Health, Tel: 0911739694,

E-mail: ayalewastat@yahoo.com, P.O.Box: 1643, Awassa; ${ }^{2}$ University of Gondar, College of Medicine and Health Sciences, School of Public Health, Tel: 0918771312, E-mail: felekeam@yahoo.com 
sleeping under any kind of net (23). In 2004 in Ethiopia, $6 \%$ of children slept under ITN the prior night. The proportion was the same for pregnant women in the same year $(24,25)$. This was just about one-tenth of the Abuja target and achieving the target in the remaining one year would be a real challenge.

Apart from coverage, issues regarding the utilization of ITNs are very crucial. This is because the ITNs that are available at a household level may be left unused or even if they are used, vulnerable members of the household may not be given priority and/ or the usage may be intermittent. The maximum malaria reduction impact of ITNs will only be achieved if people acquire nets, treat/ re-treat them, make sure that the most vulnerable household members sleep under them, and use nets all year round (26). Discrepancies between possession and utilization have been elicited by studies carried out in different African countries (27-29).

Yet, there is no properly documented evidence regarding the coverage and utilization of ITNs in the study locality. This study was, therefore, designed to investigate the possession, utilization and factors affecting possession and utilization of ITNs in Arbaminch Town and the malarious rural villages of Arbaminch Zuria District. This study also helped to evaluate the local ITN programs with reference to the Abuja targets.

\section{Methods}

A community based cross-sectional study was conducted at Arbaminch Town and the surrounding malarious rural villages of Arbaminch Zuria District from $22^{\text {nd }}$ January to $1^{\text {st }}$ February 2007. Arbaminch Town is located $505 \mathrm{Kms}$ south of Addis Ababa, the Capital City of Ethiopia. Arbaminch Town is administratively divided in to four 'kifle-ketemas' (sub-towns) and sixteen 'kebeles' all of which are malarious. Arbaminch Zuria District consists of 30 kebeles of which 11 are malarious. The total population of the study area (Arbaminch Town plus the malarious villages of Arbaminch Zuria District) is 141, 779. The total number of households is estimated to be 28,354 with an average household size of 5. The study subjects were households in selected 'kebeles' of Arbaminch Town and Arbaminch Zuria District.

The sample size was calculated using the standard formula for estimating a single proportion, $\mathbf{n}=\mathbf{Z}^{\mathbf{2}} \mathbf{p q} / \mathbf{W}^{\mathbf{2}}$. The assumptions made were: an expected proportion (ITN coverage) of 11\% (from the 2004 NetMark survey in Ethiopia (25)), 95\% confidence level and a 3\% tolerable error. Accordingly, the sample size required for this study was 413 households. Adding 10\% for nonresponse, the grand total sample size required was 454 households.

The sampling was accomplished in two stages. Initially 8 kebeles [4 urban and 4 rural] were selected randomly using the lottery method. Next, data collectors went to the approximate centre of each selected kebele and span a pen. Then the households towards which the ball point of the pen indicated were serially included into the study (proximity sampling). The number of households which were included into the study in each kebele was proportional to the total number of households in the kebele.

Data were collected using structured, pre-tested and interviewer-administered questionnaire. Some questions in the questionnaire were adapted from the NetMark Baseline Household Evaluation Survey Instrument (30) and from the suggested questions to be included for measuring core indicators for population coverage for Roll Back Malaria (31). The questionnaire included variables related to socio-demographic characteristics of households, number of household members, presence of high risk groups in the household, net possession, net utilization, etc. The questionnaire was initially prepared in English and then translated to Amharic. It was the Amharic version of the questionnaire that was used for data collection.

In households where there were married couples, the husband or the wife (preferably the wife if both are available at the same time) responded to the questionnaire. In other circumstances (when there were no married couples), the head of the household responded to the questionnaire. If the appropriate respondent was not available in the house during initial visit, revisits were considered to contact the appropriate person. The questionnaire was administered by 8 experienced interviewers who completed $12^{\text {th }}$ grade in the former curriculum. In households where mosquito nets were reported to be present, interviewers observed and confirmed the presence of the net. Moreover, when the mosquito nets were reported to be in use at that time, the interviewer checked if the net had been hanged at the place where people sleep during the interview in the day time. Four supervisors were assigned to strictly supervise the data collection.

Data entry and analysis were performed using SPSS 11.0 for windows. Univariate, bivariate and multivariate analyses were carried out. All statistical tests of significance were done at $\alpha=0.05$.

The study was conducted after obtaining ethical clearance from the Research and Publication Office of the University of Gondar. Permissions were obtained from different administrative officials of the study area. Verbal consent was also obtained from the respondents after a thorough explanation of the purpose of the study.

For uniformity of understanding concepts, here is a definition of terms. Coverage was the proportion of 
households that own at least one mosquito net at the time of the study.

Utilization referred to the proportion of households that owned a mosquito net in which one or more members of the household reportedly slept under the net the night preceding the study.

High risk group referred to pregnant women and/ or under five children.

(Mosquito) net referred to any mosquito net (treated/ untreated/ unspecified).

\section{Results}

\section{Socio-Demographic Information}

All the proposed 454 households were studied thus making the response rate for this study $100 \%$ (Table 1 ).

The total population of the studied households was 2,183 with an average $( \pm \mathrm{SD})$ household size of $4.8( \pm 2.05)$. Of the total population identified, $20(0.9 \%)$ were pregnant women, $268(12.3 \%)$ were children under five years, 592 $(27.1 \%)$ were children 5-14 years and 611 (28.0\%) were non-pregnant women. High risk groups were identified in $46.7 \%$ of the studied households. The average ( \pm SD) number of sleeping places per $\mathrm{HH}$ was $2.54( \pm 1.04)$.

\section{Mosquito Net Possession}

Of the 454 households included into this study, 341 possessed at least one net and 267 possessed at least one ITN, thus making the coverage for any mosquito net and for ITN $75.1 \%$ and $58.8 \%$ respectively. [However, coverage with at leas two mosquito nets of any type and ITNs respectively was $40.3 \%$ and $28.9 \%$.] The total number of mosquito nets identified by this study was 602 (222 in urban areas and 380 in rural areas) of which $75.3 \%$ were ITNs. Of the total ITNs identified, 48.8\% were LLINs.

The coverage for any mosquito net in urban areas was $62.6 \%$, whereas in rural areas $87.1 \%$. This difference was statistically significant [OR $(95 \% \mathrm{CI})=6.86(3.90-12.04)]$. There was also a statistically significant difference between urban and rural areas in ITN coverage which was $43.3 \%$ for urban and $73.7 \%$ for rural households [OR $(95 \% \mathrm{CI})=4.91(3.19-7.56)]$. The number of mosquito nets identified per household ranged from 1 to 5 with an average $( \pm \mathrm{SD})$ distribution per $\mathrm{HH}$ of $1.3( \pm 1.07)$ for any net and $0.998( \pm 1.05)$ for ITNs. The mean $( \pm$ SD) number of nets per $\mathrm{HH}$ in urban areas was $1( \pm 0.97)$ and in rural areas $1.6( \pm 1.06)$. Independent samples $\mathrm{T}$-test for the difference in the mean number of mosquito nets per $\mathrm{HH}$ between urban and rural residents showed a statistically significant difference $(\mathrm{t}=-6.67 ; \mathrm{P}<0.001)$.
Table 1: Socio-demographic background of the respondents, Arbaminch Town and the malarious areas of Arbaminch Zuria District, Southern Ethiopia, Feb. 2007.

\begin{tabular}{|c|c|c|}
\hline Variables $(n=454)$ & Number & Percent \\
\hline \multicolumn{3}{|l|}{ Place of residence } \\
\hline Urban & 222 & 48.9 \\
\hline Rural & 232 & 51.1 \\
\hline \multicolumn{3}{|l|}{ Sex of respondent } \\
\hline Male & 106 & 23.3 \\
\hline Female & 348 & 76.7 \\
\hline \multicolumn{3}{|l|}{$\begin{array}{l}\text { Responsibility of } \\
\text { respondent in the } \mathrm{HH}\end{array}$} \\
\hline Head of $\mathrm{HH}$ & 179 & 39.4 \\
\hline Wife of head of $\mathrm{HH}$ & 275 & 60.6 \\
\hline \multicolumn{3}{|l|}{ Sex of head of $\mathrm{HH}$} \\
\hline Male & 280 & 61.7 \\
\hline Female & 174 & 38.3 \\
\hline \multicolumn{3}{|l|}{ Age of head of $\mathrm{HH}$ (years) } \\
\hline $18-30$ & 108 & 23.8 \\
\hline $31-45$ & 206 & 45.4 \\
\hline $46-60$ & 103 & 22.7 \\
\hline$\geq 61$ & 37 & 8.1 \\
\hline \multicolumn{3}{|l|}{$\begin{array}{l}\text { Educational status of head } \\
\text { of } \mathrm{HH}\end{array}$} \\
\hline Can't read and write & 142 & 31.3 \\
\hline Can read and write & 10 & 2.2 \\
\hline $\begin{array}{l}\text { Attended primary school } \\
{[1-8]}\end{array}$ & 164 & 36.1 \\
\hline $\begin{array}{l}\text { Attended secondary } \\
\text { school [9-12] }\end{array}$ & 88 & 19.4 \\
\hline $\begin{array}{l}\text { Attended higher education } \\
\text { [institute/ college/ } \\
\text { university] }\end{array}$ & 50 & 11.0 \\
\hline \multicolumn{3}{|l|}{ Occupation of head of $\mathrm{HH}$} \\
\hline Farmer & 167 & 36.8 \\
\hline Trader & 44 & 9.7 \\
\hline Government employee & 88 & 19.4 \\
\hline Housewife & 79 & 17.4 \\
\hline Daily laborer & 38 & 8.4 \\
\hline Local drink seller & 8 & 1.8 \\
\hline NGO employee & 4 & 0.9 \\
\hline Other & 21 & 4.6 \\
\hline \multicolumn{3}{|l|}{$\begin{array}{l}\text { Average monthly income of } \\
\text { head of HH (Birr) }\end{array}$} \\
\hline$<235$ & 187 & 41.2 \\
\hline $235-540$ & 154 & 33.9 \\
\hline $541-895$ & 70 & 15.4 \\
\hline$\geq 896$ & 43 & 9.5 \\
\hline \multicolumn{3}{|l|}{ Presence of radio in the $\mathrm{HH}$} \\
\hline Yes & 358 & 78.9 \\
\hline No & 96 & 21.1 \\
\hline \multicolumn{3}{|l|}{$\begin{array}{l}\text { Presence of high risk } \\
\text { groups in the HH }\end{array}$} \\
\hline Yes & 212 & 46.7 \\
\hline No & 242 & 53.3 \\
\hline
\end{tabular}


Table 2: Mosquito net possession among the studied households, Arbaminch Town and the malarious villages of Arbaminch Zuria District, Southern Ethiopia, Feb. 2007

\begin{tabular}{|c|c|c|}
\hline Variable & Number & Percent \\
\hline \multicolumn{3}{|c|}{ Possession of at least one mosquito net $(n=454)$} \\
\hline Yes & 341 & 75.1 \\
\hline No & 113 & 24.9 \\
\hline \multicolumn{3}{|l|}{ Possession of at least one ITN (n=454) } \\
\hline Yes & 267 & 58.8 \\
\hline No & 187 & 41.2 \\
\hline \multicolumn{3}{|c|}{ Possession of at least 2 mosquito nets ( $n-454)$} \\
\hline Yes & 183 & 40.3 \\
\hline No & 271 & 59.7 \\
\hline \multicolumn{3}{|l|}{ Possession of at least 2 ITNs $(n=454)$} \\
\hline Yes & 131 & 28.9 \\
\hline No & 323 & 71.1 \\
\hline \multicolumn{3}{|c|}{ Number of any mosquito net possessed $(n=341)$} \\
\hline One & 158 & 46.3 \\
\hline Two or more & 183 & 53.7 \\
\hline \multicolumn{3}{|l|}{ Number of ITNs possessed $(n=267)$} \\
\hline One & 136 & 50.9 \\
\hline Two or more & 131 & 49.1 \\
\hline \multicolumn{3}{|c|}{ Cumulative number of nets identified during the study } \\
\hline Any mosquito net & 602 & 100 \\
\hline ITNs & 453 & 75.3 \\
\hline \multicolumn{3}{|c|}{ Nets observed and presence confirmed $(n=602)$} \\
\hline Yes & 597 & 96.2 \\
\hline No & 23 & 3.8 \\
\hline \multicolumn{3}{|l|}{ Source of nets $(n=602)$} \\
\hline From health institution, freely & 364 & 60.5 \\
\hline From health institution, with payment & 52 & 8.6 \\
\hline Bought from market/ shop & 146 & 24.3 \\
\hline From other source, freely & 21 & 3.5 \\
\hline From other source, with payment & 19 & 3.2 \\
\hline \multicolumn{3}{|c|}{ Duration of possession of the nets $(n=602)$} \\
\hline$<1$ year & 167 & 27.7 \\
\hline $1-5$ years & 424 & 70.4 \\
\hline$\geq 6$ years & 9 & 1.5 \\
\hline Don't remember & 2 & 0.3 \\
\hline \multicolumn{3}{|l|}{ Brand of nets $(n=602)$} \\
\hline PermaNet & 221 & 36.7 \\
\hline UNICEF & 103 & 17.1 \\
\hline SafeNite & 78 & 13.0 \\
\hline PowerNet & 3 & 0.5 \\
\hline Olyset & 1 & 0.2 \\
\hline NetMark & 1 & 0.2 \\
\hline Unknown & 195 & 32.4 \\
\hline \multicolumn{3}{|c|}{ Reason for not owning any mosquito nets $(n=113)$} \\
\hline inability to afford the price & 59 & 52.2 \\
\hline Shortage of nets during free provision & 17 & 15.0 \\
\hline Not knowing its use & 15 & 13.3 \\
\hline Absence of mosquitoes & 6 & 5.3 \\
\hline Using other preventive methods & 7 & 6.2 \\
\hline Not knowing where to find it & 4 & 3.6 \\
\hline Other reason & 5 & 4.4 \\
\hline \multicolumn{3}{|c|}{ Desire to possess mosquito nets in the future $(n=113)$} \\
\hline Yes & 103 & 91.2 \\
\hline No & 5 & 4.4 \\
\hline Can't tell & 5 & 4.4 \\
\hline \multicolumn{3}{|l|}{ Preferred way of obtaining nets } \\
\hline If distributed freely & 64 & 62.1 \\
\hline If sold with discount & 35 & 34.0 \\
\hline If sold at any price & 4 & 3.9 \\
\hline \multicolumn{3}{|l|}{ Affordable discounted price $(n=35)$} \\
\hline$<10$ Birr & 19 & 54.3 \\
\hline 10-20 Birr & 16 & 45.7 \\
\hline
\end{tabular}


The majority $(60.5 \%)$ of the nets identified during the study were provided to the households freely by the local health authorities. A great proportion (92.6\%) of the nets in rural areas were obtained freely while only $14.9 \%$ of the nets identified in urban areas were obtained for free. About $85 \%$ of the nets identified in urban areas were purchased. The mean $( \pm \mathrm{SD})$ price of the nets purchased was $33.3( \pm 14.6)$ Birr. On the average $( \pm \mathrm{SD})$, the nets have been possessed for a duration of $1.5( \pm 1.5)$ years (Table 2).

\section{Mosquito Net Utilization}

Of the 341 households who owned mosquito nets, $82.7 \%$ reported that they used their nets at one time or another, while the remaining $17.3 \%$ did not use their available nets at all. And of those who reportedly used their nets, $77.3 \%$ used their nets consistently throughout the year, whereas $22.7 \%$ used their nets intermittently. Fifty nine $(92.2 \%)$ of those who used their nets intermittently reported that they used their nets during or after rainy season. The proportion of households that owned at least one mosquito net in which any member of the household slept under a net the night prior to the study was $71.0 \%$ (Table 3). The utilization rate for any net by any member of the household the night prior to the study was $59.0 \%$ in urban areas and $79.2 \%$ in rural areas. This difference, however, is not statistically significant [OR (95\% $\mathrm{CI})=1.42(0.53-3.83)]$. The utilization rate for ITNs by any member of the household the night prior to the study was $73.0 \%$ (62.5\% in urban areas and $78.9 \%$ in rural areas). The difference in utilization rate of ITNs between urban and rural areas was not statistically significant [OR $(95 \% \mathrm{CI})=1.71(0.66-4.39)]$. Ten $(50 \%)$ of the 20 pregnant women identified slept under any net and 7 (35\%) slept under ITNs the night prior to the study. Of the 268 under five children identified during this study, $53.7 \%$ and $40.3 \%$ slept under any net and ITNs respectively the night prior to the study. Thirty two point one percent of the 592 children 5-14 years found during this study slept under any net and $27.9 \%$ slept under ITNs the night prior to the study. The reported utilization rate the night prior to the study by the 611 non-pregnant women identified during this study was $39.4 \%$ and $30.4 \%$ for any net and ITNs respectively (Figure 1).

Table 3: Mosquito net utilization pattern, Arbaminch Town and the malarious villages of Arbaminch Zuria District, Southern Ethiopia, Feb. 2007

\begin{tabular}{|c|c|c|}
\hline Variables & Number & Percent \\
\hline \multicolumn{3}{|l|}{ Using the available nets $(n=341)$} \\
\hline Yes & 282 & 82.7 \\
\hline No & 59 & 17.3 \\
\hline \multicolumn{3}{|l|}{ Frequency of using the nets? $(n=282)$} \\
\hline Consistently throughout the year & 218 & 77.3 \\
\hline Intermittently & 64 & 22.7 \\
\hline \multicolumn{3}{|c|}{ Times when intermittent users use their nets $(n=64)$} \\
\hline During rainy season & 39 & 60.9 \\
\hline After rainy season & 20 & 31.3 \\
\hline During dry season & 2 & 3.1 \\
\hline As they like & 2 & 3.1 \\
\hline When hearing mosquitoes buzzing & 1 & 1.6 \\
\hline \multicolumn{3}{|l|}{ Use of any net the preceding night $(n=341)$} \\
\hline Yes & 242 & 71.0 \\
\hline No & 99 & 29.0 \\
\hline \multicolumn{3}{|c|}{ Did any one sleep under an ITN last night? $(n=267)$} \\
\hline Yes & 195 & 73.0 \\
\hline No & 72 & 27.0 \\
\hline \multicolumn{3}{|l|}{ Reason why nets are not being used $(n=59)$} \\
\hline Absence of mosquitoes & 17 & 28.8 \\
\hline old and worn out net & 17 & 28.8 \\
\hline It is hot sleeping under a net & 6 & 10.2 \\
\hline Children may get trapped in it & 5 & 8.4 \\
\hline Lack of appropriate place for hanging the net & 4 & 6.8 \\
\hline It takes time to tuck in the net each night & 4 & 6.8 \\
\hline Difficult to get up at night & 4 & 6.8 \\
\hline Other reason & 2 & 3.4 \\
\hline
\end{tabular}

\section{Predictors of Mosquito Net Possession}

After controlling for the effects of potentially confounding variables using multivariate stepwise backward logistic regression, education of head of household, income of head of household, place of residence of the household and presence of high risk groups in the household were found to be statistically significant predictors of mosquito net possession. Education of head of household had a strong positive association with net possession [OR $(95 \% \mathrm{CI})=1.29$ (1.02-1.62)]. As income of head of household increases, the odds of possessing a net was found to increase [OR 
$(95 \% \mathrm{CI})=1.69(1.25-2.29)]$. Being a rural resident was also found to increase the odds of possessing a net [OR $(95 \% \mathrm{CI})=6.86(3.90-12.04)]$. And presence of high risk groups in the household was found to have a significant positive association with net ownership [OR (95\% $\mathrm{CI}=1.69(1.04-2.75)]$ (Table 4).

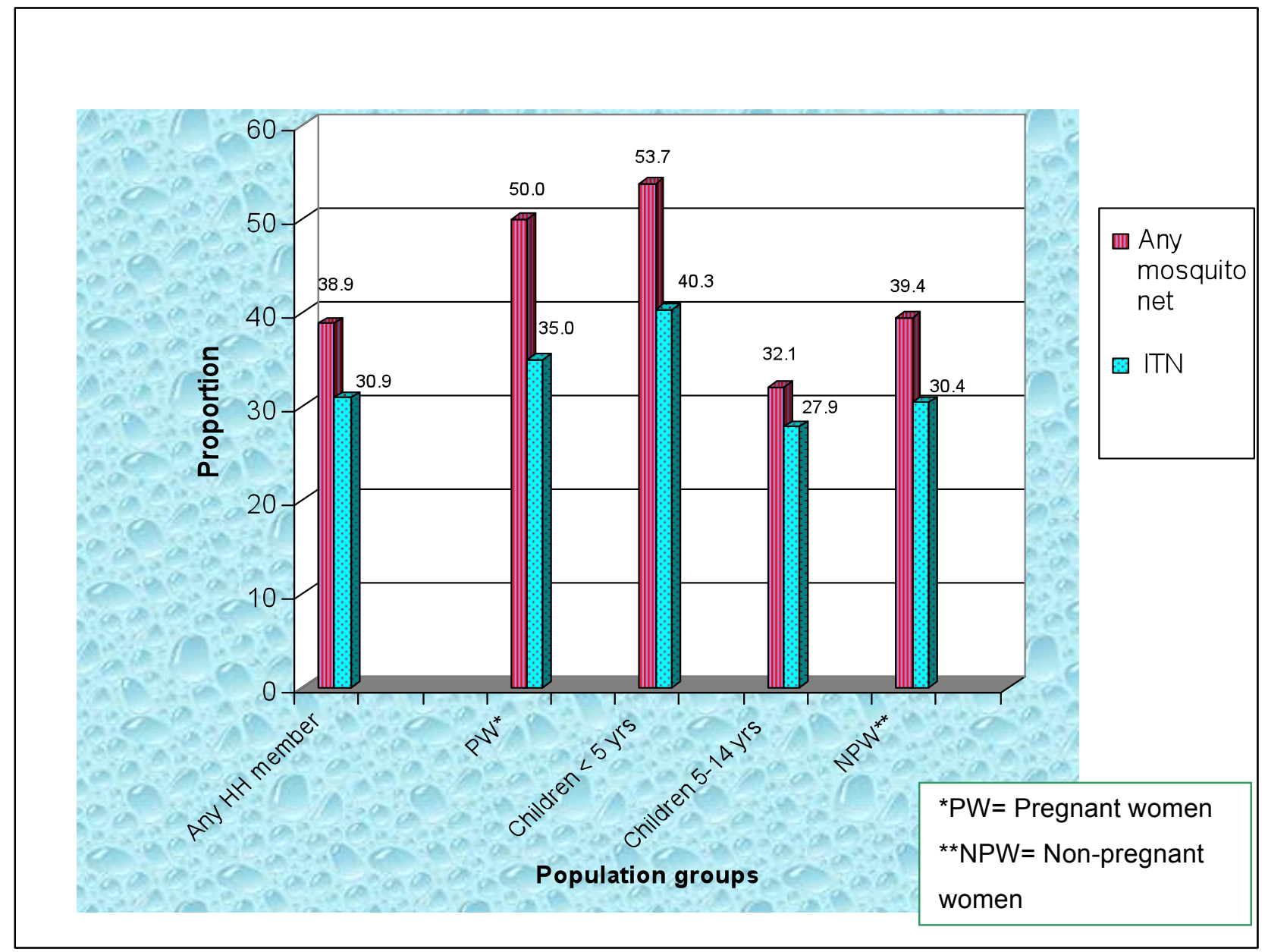

Figure 1: Mosquito net Utilization pattern the night prior to the study by specific population groups, Arbaminch Town and the malarious villages of Arbaminch Zuria District, Southern Ethiopia, February 2007.

Table 4: Predictors of mosquito net possession and utilization among the studied households, Arbaminch Town and the malarious villages of Arbaminch Zuria District, Southern Ethiopia, Feb. 2007

\begin{tabular}{|c|c|c|c|c|c|c|}
\hline \multirow{2}{*}{ Predictor variable } & \multicolumn{3}{|c|}{ Bivariate analysis } & \multicolumn{3}{|c|}{ Multivariate analysis } \\
\hline & $\boldsymbol{\beta}$ & P-value & OR $(95 \% \mathrm{Cl})$ & $\beta$ & P-value & OR (95\% CI) \\
\hline \multicolumn{7}{|l|}{ Possession } \\
\hline Education of head of household & 1.131 & 0.1 .1 & $1.14(0.98-1.33)$ & 0.251 & 0.003 & $1.29(1.02-1.62)$ \\
\hline Income of head of household & 0.454 & $<0.001$ & $1.58(1.23-2.03)$ & 0.525 & 0.001 & $1.69(1.25-2.29)$ \\
\hline Place of residence of household* & 1.391 & $<0.001$ & $4.02(2.51-6.43)$ & 1.925 & $<0.001$ & $6.86(3.90-12.04)$ \\
\hline Presence of HRGs in the household** & 0.773 & 0.001 & $2.17(1.39-3.38)$ & 0.525 & 0.035 & $1.69(1.04-2.75)$ \\
\hline \multicolumn{7}{|l|}{ Utilization by any $\mathrm{HH}$ member } \\
\hline Sex of head of $\mathrm{HH}^{* *}$ & -0.773 & 0.006 & $0.46(0.27-0.81)$ & -0.815 & 0.002 & $0.44(0.26-0.75)$ \\
\hline Income of Head of $\mathrm{HH}$ & -0.238 & 0.105 & $0.79(0.59-1.05)$ & -0.309 & 0.019 & $0.73(0.57-0.95)$ \\
\hline Presence of radio in the $\mathrm{HH}^{\star *}$ & -0.701 & 0.005 & $0.49(0.24-1.02)$ & -0.823 & 0.035 & $0.44(0.21-0.94)$ \\
\hline \multicolumn{7}{|l|}{ Utilization by HRGs **** } \\
\hline Education of head of $\mathrm{HH}$ & 0.272 & 0.016 & $1.31(1.05-1.64)$ & 0.415 & 0.001 & $1.51(1.18-1.94)$ \\
\hline Place of residence of $\mathrm{HH}^{*}$ & 0.474 & 0.097 & $1.61(0.92-2.81)$ & 0.913 & 0.005 & $2.49(1.31-4.74)$ \\
\hline
\end{tabular}




\section{Predictors of Mosquito Net Utilization}

Multivariate stepwise backward logistic regression yielded sex of head of households, monthly income of head of households and presence of radio in the households to be statistically significant predictors of mosquito net utilization by any household member the night preceding the study. Female head of households decreased the odds of net utilization [OR $(95 \% \mathrm{CI})=0.44$ (0.26-0.75)]. With increase in income of head of household, the odds of net utilization was found to decrease $[\mathrm{OR}(95 \% \mathrm{CI})=0.73(0.57-0.95)]$. Presence of radio in the household was also negatively associated with net utilization [OR $(95 \% \mathrm{CI})=0.44(0.21-0.94)]$.

For mosquito net utilization by high risk groups, education of head of household and place of residence of the household were found to be the only statistically significant predictors. An increase in the educational level of head of household increased the odds utilization by high risk groups [OR $(95 \% \mathrm{CI})=1.51(1.18-1.94)]$. Rural residence was also found to increase the odds of mosquito net utilization by high risk groups [OR $(95 \%$ $C I)=2.49(1.31-4.74)]($ Table 4).

\section{Discussion}

In this study, the coverage for any mosquito net and ITNs was found to be $75.1 \%$ and $58.8 \%$ respectively. However, the coverage with at least two mosquito nets of any type and ITNs respectively was $40.3 \%$ and $28.9 \%$. Thus, in reference to the national strategic plan of the Federal Ministry of Health which aims to attain a coverage of $60 \%$ with at least two ITNs by 2007 (32), the coverage in the study area could be considered low. Yet, the coverage found by this study is higher than the coverage reports of the Ethiopian DHS 2005 in which the coverage for any net and for ITNs was 5.7\% and 3.4\% respectively (33), NetMark 2004 survey in which the coverage for any net and for ITNs was $25 \%$ and $11 \%$ respectively (25) and a national baseline survey conducted in 1999 in which the coverage for any net was $5.3 \%$ (34). The difference from the DHS 2005 report could be explained by the difference in the areas covered by the study; the DHS provides reports for areas with significantly lesser risk of malaria and higher risk of malaria merged together while this study is conducted in a malaria-endemic area. The difference from the NetMark 2004 survey report could be explained especially by the time gap between the NetMark survey and this study during which the distribution of ITNs was going on. The National Baseline Survey of 1999 was conducted before the implementation of ITN projects in the country and the wide gap in coverage between the previous and current time could be an indicator of the progress achieved since the implementation of ITN projects.

It was found by this study that the coverage both for any net and ITNs was higher in rural areas compared to urban areas. Other studies have documented higher coverage in urban areas relative to rural areas $(3,24,25,33,35)$. As identified by this study, about $92.6 \%$ of the nets identified in rural areas were obtained freely while only about $15 \%$ of the nets in urban areas were obtained so. Thus, while cost which is often cited as a major constraint for the possession of ITNs $(3,25,26,36)$ is not a considerable problem in the rural areas addressed by this study, it may be a major problem in the urban areas. As the economically weak segments of the urban population may not afford (though subsidized) to buy ITNs, the coverage in urban areas may be lower than in rural areas where nets are distributed almost entirely freely.

In this study, of the 341 net owner households, about $17 \%$ do not use their nets at all while of those who reportedly use their nets, about $23 \%$ use their nets intermittently. The utilization rate by any household member for any net and ITNs was $71 \%$ and $73 \%$ respectively the night preceding the study. These findings justify that there is a considerable discrepancy between possession and utilization of mosquito nets as also elicited by other studies $(3,25,27,28)$.

Contrary to findings of other studies $(25,33)$, in this study, the utilization in rural areas was found to be higher than those in urban areas, though not statistically significant. One possible explanation for that could be that as the majority of the nets in rural areas were obtained freely through the local health authorities, the net owners might have been provided with appropriate health information regarding the use of ITNs during the provision of the nets. The presence of health extension workers in all the studied rural "kebeles", but none in the urban "kebeles", could be another possible explanation.

The proportion of pregnant women and children under five years who slept under an ITN the night prior to the study was $35 \%$ and $40.3 \%$ respectively. These figures are higher than the figures reported by the NetMark 2004 survey (25) in which the proportion was $6 \%$ for both pregnant women and under-fives. One possible reason for this remarkable difference could be the works done such as distribution of ITNs and health information dissemination after the NetMark survey was conducted. When interpreted with reference to the Abuja targets in which $60 \%$ of under-fives and pregnant women are expected to sleep under ITNs by the year $2005(10,19$, 21 ), use of ITNs by these specific groups identified by this study is very low. However, according to the national stands on ITNs, Ethiopia has the plan to achieve the figures set on the Abuja Declaration by 2007 (32). As the distribution of ITNs in the study area was going on even after the data were collected, the proportion of high risk groups sleeping under ITNs may increase before the end of 2007. But as the number of pregnant women identified by this study is very small (only 20), it would be very difficult to draw firm conclusions regarding use of ITNs 
by pregnant women. Hence, the results for pregnant women must be interpreted bearing this small number in mind.

Education of head of household in this study was found to be an important predictor of mosquito net possession. That is, an increase in educational level of the household head was associated with increased odds of possessing a net. This could be explained firstly by the possible increase in awareness of mosquito nets and their advantages and probably better comprehending capability of mass media messages related to mosquito nets with increase in educational status. Secondly, the possibility of earning a better income with increase in educational status may increase the likelihood of possessing a net. Income, as also found by another study (35), was major predictor of mosquito net possession which could be explained by the increase in purchasing capability of mosquito nets with increase in income. Being a rural resident was also found to increase the odds of possessing a net by a factor of 6.86 which could be due to the explanation given earlier in this discussion. As households with high risk groups are often given precedence over other households during free distribution of ITNs, presence of high risk groups in the household was also found to be another predictor of mosquito net possession.

In this study, households which have female heads have 0.44 times lesser odds of using their nets the preceding night. This negative association might have resulted from the level of education of the female household heads; about $41 \%$ of the female household heads were illiterate while only about $25 \%$ of the male household heads were so. The odds of any household member sleeping under a mosquito net the prior night was also found to decrease with increase in the income level of the household head. It was discussed earlier, however, that with increase in income, the odds of possessing a net increases. But this high level of possession may not necessarily translate into a high level of utilization. In fact, what is found by this study is, while the odds of possessing a net with increase in income increases, the reverse happens to utilization. This could be because those with higher income may be able to purchase and use other alternative preventive measures such as insecticidal aerosols. The negative association of possession of radio with utilization of nets could also be explained by the possible exposure to information regarding the alternative methods of preventing mosquito bites as result of which alternatives other than mosquito nets may be used.

Nonetheless, worth noting, in the progress of the study, it was a dry season at which time the population of mosquitoes and thereby the transmission of malaria was relatively less. Many people do not feel they need to use nets in the dry season, when there may be fewer nuisance mosquitoes (26). Thus, if the study had been conducted in the high malaria transmission season (SeptemberDecember), the findings especially regarding the utilization of ITNs might have been different.

In conclusion, the coverage of mosquito nets in the study area was high compared to the results of studies conducted previously in different parts of the country. Yet, there is a wide gap between possession and utilization of nets. Use of ITNs by high risk groups was found to be lower than the Abuja target. Education, income and sex of head of households, place of residence of households, presence of high risk groups in the households and possession of radio were found to influence possession and/or utilization of nets in one way or another. Appropriate BCC interventions are required to narrow the gap between coverage and utilization of ITNs and to increase use of ITNs by high risk groups. Besides, provision of ITNs with moderate cost or for free by government, NGOs and others concerned must give emphasis to the poor.

\section{Acknowledgments}

Our sincere thanks go to the University of Gondar for providing financial support for this study. We are also very much indebted to Arbaminch College of Health Sciences for providing us with vehicle during the data collection. Gamogofa Zone Health Department, Arbaminch Zuria District Health Office and Arbaminch Town Administration Health Office also deserve special thanks for their cooperation and for giving us all the invaluable information we demanded from the beginning to the end of this work. Last, but not least, we thank the study participants who willingly took part in this study.

\section{References}

1. Nahlen BL, Clark JP, and Alnwick D. Insecticidetreated Bed Nets. Am J Trop Med Hyg. 2003;68(suppl 4):1-2.

2. Ministry of Health/UNICEF in Ethiopia. GUIDE for program managers on the use of insecticide-treated nets in Ethiopia. July 2002.

3. Okrah J, Traore C, Pale A, Sommerfeld J and Müller O. Community factors associated with malaria prevention by mosquito nets: an exploratory study in rural Burkina Faso. Tropical Medicine and International Health 2002;7 (Issue 3):240.

4. Greenwood BM, Bojang K, Whitty CJ, Targett GA. Malaria. Lancet 2005;365(9469):1487-98.

5. S. Meek, J. Hill, J. Webster. The evidence base for interventions to reduce malaria mortality in low and middle income countries. Commission on Macroeconomics and Health (CMH) Working Paper Serious. Paper No. WG5: 6. September 2001.

6. Roll Back Malaria. Section I: Global malaria situation. World Malaria Report 2005. Available at: http://rbm.who.int/wmr2005/html/1-1.htm.

(Accessed on: 15/ 08/2006). 
7. Malaria and Other Vector Borne Diseases Control Unit, Epidemiology and AIDS Control Department, Ministry of Health. Malaria Diagnosis and Treatment Guidelines for Health Workers in Ethiopia. Addis Ababa; July 1999.

8. Federal Democratic Republic of Ethiopia, Ministry of Health. Malaria Diagnosis and Treatment Guidelines for Health Workers in Ethiopia. Second Edition. Addis Ababa; July 2004.

9. Roll Back Malaria Monitoring and Evaluation. Country Profile: Ethiopia. World Malaria Report 2005. Available at: http://rbm.who.int/wmr2005/ profiles/ethiopia.pdf. (Accessed on: 15/08/2006).

10. Negash K, Jima D, Nafo-Traore F, et al. Ethiopian Roll Back Malaria Consultative Mission: Essential Actions to Support the Attainment of the Abuja Targets. $16^{\text {th }}$ to $20^{\text {th }}$ February 2004 .

11. Ministry of Health, Planning and Programming Department, Health Information Processing and Documentation Team. Health and Health Related Indicators. 2004/ 2005.

12. Lengeler $\mathrm{C}$. Insecticide-treated nets for malaria control: real gains. Bulletin of the World Health Organization. 2004;82:84.

13. Adongo PB, Kirkwood B, Kendall C. How local community knowledge about malaria affects insecticide-treated net use in northern Ghana. Trop. Med. Int. Health 2005;10(4):366-78.

14. Abdulla S, Gemperli A, Mukasa O, et al. Spatial effects of the social marketing of insecticide-treated nets on malaria morbidity. Trop. Med Int. Health 2005;10(1):11-8.

15. Rowland M, Webster J, Saleh P, et al. Prevention of malaria in Afghanistan through social marketing of insecticide-treated nets: Evaluation of coverage and effectiveness by cross-sectional surveys and passive surveillance. Tropical Medicine and International Health 2002;7(issue 10):813

16. Phillips-Howard PA, Nahlen BL, Alaii JA, et al. The efficacy of permethrin treated bed nets on child mortality and morbidity in western Kenya I. Development of infrastructure and description of study site. Am. J. Trop. Med. Hyg. 2003;68(4 suppl):3-9.

17. Ter Kuile FO, Terloun DJ, Kariuki SK, et al. Impact of Permethrin Treated Bed Nets on Malaria, Anemia and Growth in Infants in an Area of Intense Perennial Malaria Transmission in Western Kenya. Am. J. Trop. Med. Hyg. 2003: 68(4 suppl): 68-77

18. Anyanwu EC, Ehiri JE, Kanu I, Morad M, Ventegodt S, Merrick J. Assessing the effects of long-term exposure to insecticide treated mosquito nets in the control of malaria in endemic regions. Scientific world Journal 2004; 4:978-88.

19. Roll Back Malaria. 2001-2010 United Nations Decade to Roll Back Malaria: Insecticide-treated Mosquito Nets. RBM info sheet. Accessed through: http:/www.rbm.who.int. (Accessed on: 15/ 08/ 2006).

20. Gamble C, Ekwaru JP, Ter Kuile FO. Insecticidetreated nets for preventing malaria in pregnancy. Cochrane Database of Syst Rev. 2006 Apr 19; (2): CD003755.

21. The Abuja Declaration and the Plan of Action: An Extract from the African Summit on Roll Back Malaria, Abuja, 25 April 2000 (WHO/CDS/RBM/ 2000.17). Available at: http://www.rbm.who.int/ docs/abuja_declaration final.htm. (Accessed on: 15/ 08/2006).

22. Worrall E, Hill J, Webster J, and Mortimer J. Experience of targeting subsidies on insecticidetreated nets: What do we know and what are the knowledge gaps? Trop. Med. Int. Health 2005; 10(1): 19-31.

23. Hill J, Lines J, Rowland M. Insecticide-treated nets. Adv Parasitol. 2006; 61:77-128.

24. Academy for Educational Development, NetMark. Insecticide Treated Nets in Nigeria, Senegal, Zambia, Ghana and Ethiopia. NetMark 2004 Survey. Available at: http://www.netmarkafrica.org/research. (Accessed on: 15/ 08/ 2006).

25. Academy for Educational Development, NetMark. Insecticide Treated Nets in Ethiopia. NetMark 2004 Survey. Available at: http://www.netmarkafrica.org/ research. (Accessed on: 28/ 08/2006).

26. NetMark research 1999-2006. Available at: http:// www.netmarkafrica.org/research. (Accessed on: 15/ 08/2006).

27. Macintyre K, Keating J, Okbaldt YB, et al. Rolling out insecticide treated nets in Eritrea: examining the determinants of possession and use in malarious zones during rainy seasons. Trop Med Int Health. 2006 Jun; 11(6): 824-33.

28. Koreromp EL, Miller J, Cibulskis RE, Kabir Cham M, Alnwick D, Dye C. Monitoring mosquito net coverage for malaria control in Africa: possession versus use by children under 5 years. Trop Med Int Health. 2003 Aug; 8(8): 693-703.

29. Tsuyuoko R, Midizi SM, Dziva P, Makunike B. The acceptability of insecticide treated mosquito nets among community members in Zimbabwe. Cent Afr J Med. 2002 Jul-Aug; 48 (7-8):87-91.

30. NetMark Baseline Household Evaluation Survey Instrument. Available at: http://www.netmarkafrica. org/research. (Accessed on: 31/ 08/ 2006)

31. Roll Back Malaria, MEASURE Evaluation, World Health Organization, UNICEF. Guidelines for Core Population Coverage Indicators for Roll Back Malaria: To be obtained from household surveys. MEASURE Evaluation: Calverton, Maryland. 2004.

32. Federal Democratic Republic of Ethiopia, Ministry of Health. Insecticide Treated Nets (ITNs): National Strategic Plan for Going to Scale with Coverage and Utilization in Ethiopia, 2004-2007. August 2004. 
33. Central Statistics Agency and ORC Macro. Ethiopian Demographic and Health Survey 2005. Central Statistics Agency and ORC Macro: Addis Ababa, Ethiopia and Calverton, Maryland, USA. September 2006.

34. Jima D, Tesfaye G, Deressa W, Woyessa A, Kebede $D$, Alamirew D. Base line survey for the implementation of insecticide treated mosquito nets in Ethiopia. Ethiop J Health Dev. 2005; 19(1):16-23.
35. Haileselassie B. Assessment of insecticide treated nets coverage for malaria control in Kafta-Humera district, Tigray: Possession vs. use by high risk groups. [MPH thesis]. Department of Community Health, Faculty of Medicine, Addis Ababa University. June 2006.

36. Wiseman V, McElroy B, Conteh L, Stevens W. Malaria prevention in the Gambia: patterns of expenditure and determinants of demand at the household level. Trop Med Int Health. 2006 April; 11(4):419-31. 